\title{
S-wave velocity structure in the SE Tibetan plateau
}

\author{
Yan Cai $\cdot$ Jianping Wu $\cdot$ Weilai Wang $\cdot$ Lihua Fang $\cdot$ \\ Liping Fan
}

Received: 27 January 2016/ Accepted: 26 April 2016/Published online: 30 May 2016

(c) The Author(s) 2016. This article is published with open access at Springerlink.com

\begin{abstract}
We use observations recorded by 23 permanent and 99 temporary stations in the SE Tibetan plateau to obtain the S-wave velocity structure along two profiles by applying joint inversion with receiver functions and surface waves. The two profiles cross West Yunnan block (WYB), the Central Yunnan sub-block (CYB), South China block (SCB), and Nanpanjiang basin (NPB). The profile at $\sim 25^{\circ} \mathrm{N}$ shows that the Moho interface in the CYB is deeper than those in the WYB and the NPB, and the topography and Moho depth have clear correspondence. Beneath the Xiaojiang fault zone (XJF), there exists a crustal low-velocity zone (LVZ), crossing the XJF and expanding eastward into the SCB. The NPB is shown to be of relatively high velocity. We speculate that the eastward extrusion of the Tibetan plateau may pass through the XJF and affect its eastern region, and is resisted by the rigid NPB, which has high velocity. This may be the main cause of the crustal thickening and uplift of the topography. In the Tengchong volcanic area, the crust is shown to have alternate high- and low-velocity layers, and the upper mantle is shown to be of low velocity. We consider that the magma which exists in the crust is from the upper mantle and that the complex crustal velocity structure is related to magmatic differentiation. Between the Tengchong volcanic
\end{abstract}

\footnotetext{
Y. Cai · J. Wu $(\bowtie) \cdot$ W. Wang $\cdot$ L. Fang $\cdot$ L. Fan

Institute of Geophysics, China Earthquake Administration,

Beijing 100081, China

e-mail: wjpwu@cea-igp.ac.cn

Y. Cai

e-mail: caiyan@cea-igp.ac.cn

J. Wu $\cdot$ L. Fang

Key Laboratory of Seismic Observation and Geophysical

Imaging, Institute of Geophysics, China Earthquake

Administration, Beijing 100081, China
}

area and the XJF, the crustal velocity is relatively high. Combining these observations with other geophysical evidence, it is indicated that rock strength is high and deformation is weak in this area, which is why the level of seismicity is quite low. The profile at $\sim 23^{\circ} \mathrm{N}$ shows that the variation of the Moho depth is small from the eastern rigid block to the western active block with a wide range of LVZs. We consider that deformation to the south of the SE Tibetan Plateau is weak.

Keywords SE Tibetan plateau - Velocity structure · Receiver function - Joint inversion - Tengchong volcano

\section{Introduction}

Collision between the Indian and Eurasian plates has induced intense orogenesis, produced many active faults, and caused material to escape from the Tibetan plateau (Molnar and Tapponnier 1975; Rowley 1996). To study the uplift and deformation mechanisms in this region, researchers have proposed many models, such as eastward extrusion of crustal material, crustal thickening and uplift of the plateau, or channel flow in a weak crust (Molnar and Tapponnier 1975; Tapponnier et al. 1982; Allegre et al. 1984; Royden et al. 1997). The SE Tibetan plateau is a region which is likely to be experiencing crustal flow and eastward extrusion, so it is quite important to study and test these models in this region. Thus, research into the deep crustal structure in the Tibetan plateau is needed to deepen our understanding of its evolution mechanisms.

Under forces from the NE subduction of the Indian plate and the eastward subduction of the Myanmar microplate, the Tibetan plateau has extruded eastward. Resisted by the rigid Yangtze platform, extrusion in the study area has 
become toward the southeast. Subjected to the intense tectonic activity, there has produced many major strike-slip faults in the SE Tibetan plateau. With the intense crustal movement and strike-slip motion of the active faults, there is a clockwise rotation around the eastern Himalaya syntaxis in the SE Tibetan plateau (Replumaz and Tapponnier 2003; Shen et al. 2001; Liang et al. 2013), and the strong earthquakes occurred frequently (Fig. 1). Combined with the GPS observation data, historical earthquakes, and focal mechanism, previous studies have divided the SE Tibetan plateau into many blocks (Fig. 1). The boundary faults among these blocks are shown to be compressionshear or tension-shear, and there is intense tectonic activity near these faults (Xu et al. 2005; Cheng et al. 2012). Thus, the velocity structure and deformation of the SE Tibetan plateau have attracted much attention. Researchers have used many techniques to study the crust-mantle structures beneath this region, such as receiver function inversion, surface wave dispersion curve inversion, joint inversion, travel time inversion, and deep seismic sounding (Wu et al. 2001, 2013; Wang et al. 2003, 2007, 2014; Bai and Wang 2004; Hu et al. 2008; Li et al. 2009; Sun et al. 2014; Fan et al. 2015). However, resolutions have been limited for the observations from permanent stations. Sun et al. (2014) used dense seismic data from Chinarry to obtain the velocity structure of a

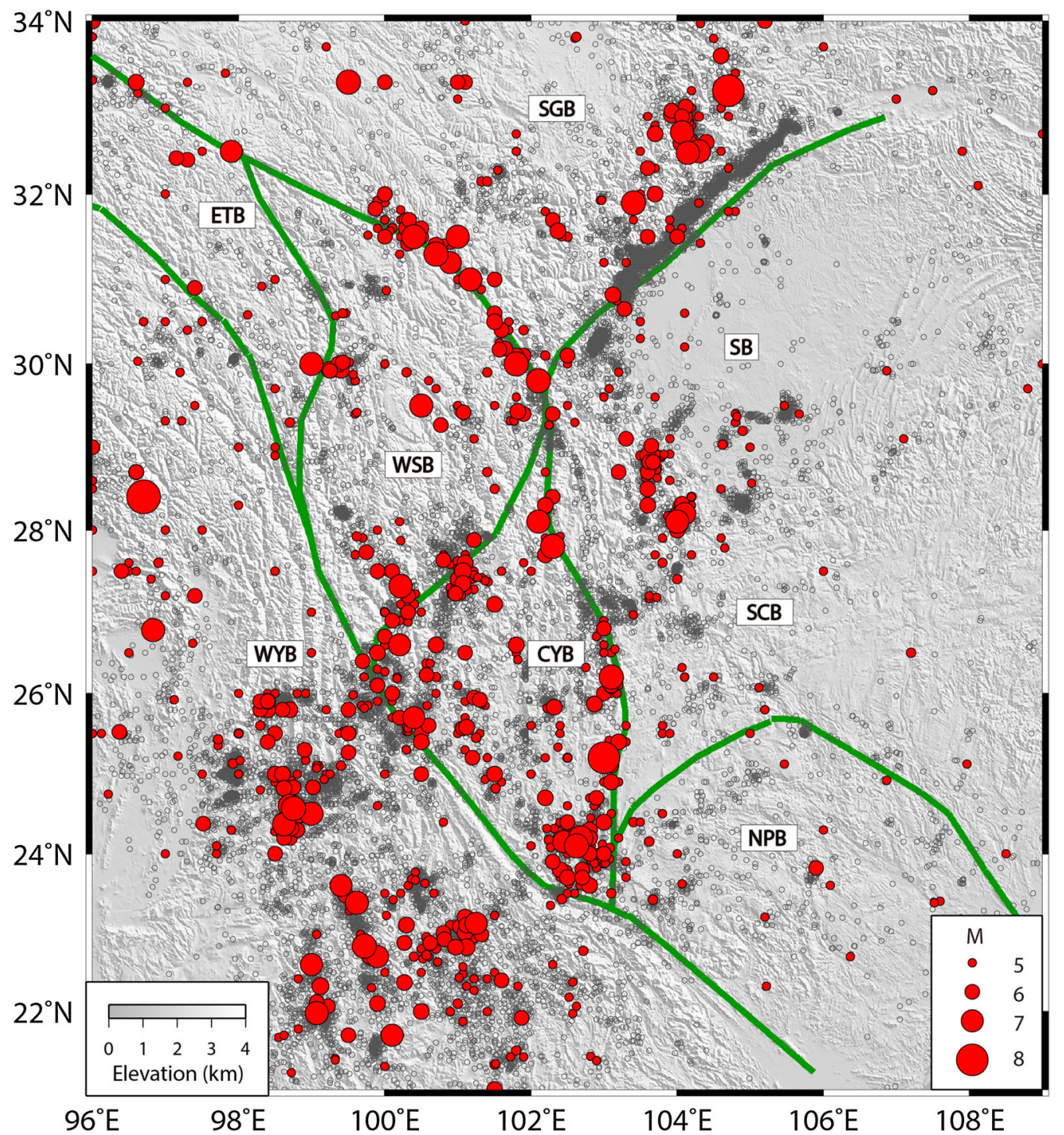

Fig. 1 Map of the blocks and tectonic boundaries in the SE Tibetan plateau. Green lines represent the boundaries between the tectonic units. The red solid circles represent the historical earthquakes with the magnitude larger than 5.0. The black open circles are the earthquakes with magnitude larger than 3.0 from 1970 to 2015 (the earthquake catalogue is from the China Earthquake Networks Center). ETB Eastern Tibet subblock, SGB Songpan-Garze block, WSB Western Sichuan sub-block, WYB Western Yunnan sub-block, $C Y B$ Central Yunnan sub-block, $S C B$ South China block, NPB Nanpanjiang basin, $S B$ Sichuan basin 
profile. They concluded that the two LVZs in the crust are crustal flow channels. Combining this with other research, we consider that the interpretation for the velocity structure should be a little different.

The youngest continental volcano in China-Tengchong volcano is located to the west of the West Yunnan block (WYB). Owing to the collision of the Indian and Eurasian plates, volcanic eruptions, geothermal activity, and crustal earthquakes are quite frequent and intense. Researchers have always been concerned with the deep structure of the volcano and its development (Qin et al. 1998; Wang et al. 2002; Wang and Gang 2004) and have obtained many important results and conclusions. These studies play an important role in predicting volcanic eruptions, understanding the relationships between the volcano and earthquakes, detecting geothermal storage and rationally utilizing geothermal resources.

In this paper, we use observation data recorded by not only the permanent stations but also the newly deployed dense seismic array in the SE Tibetan plateau to calculate receiver functions. We apply joint inversion with receiver functions and surface wave dispersion curves to obtain a high-resolution $\mathrm{S}$-wave velocity structure. These new results provide detailed information for studying the crustmantle structural features and tectonic boundary of the SE Tibetan Plateau.

\section{Data and methods}

The seismic data we used for inversion were recorded by 122 stations (Fig. 2): 23 permanent stations (Zheng et al. 2010) and 99 temporary stations. The permanent stations were in operation from 2007 to 2013. Of the temporary stations, 13 were in operation from December 2008 to December 2010 (ChinArray 2006) and 86 stations were in operation from June 2011 to November 2013 (ChinArray-Himalaya 2011).

We selected two seismic profiles with lengths of about $900 \mathrm{~km}$ and widths of $100 \mathrm{~km}$. The teleseismic records of all stations with epicentral distances of between $30^{\circ}$ and $90^{\circ}$, magnitudes $>5.5$, and $\mathrm{SNR}>4.0$ were selected to calculate receiver functions, and we chose 1436 teleseismic events (Fig. 3).

\subsection{Extracting receiver functions}

We extracted receiver functions from teleseismic P-waves using the maximum entropy deconvolution method (Burg 1972; Claerbout 1976; Wu et al. 2003). The original seismic records were processed by a band-pass filter of $0.02-2 \mathrm{~Hz}$. We applied a Gaussian filter with an $\alpha$-coefficient of 2.5 and a volume factor of 0.001 for the deconvolution method. To obtain a reliable velocity structure, we selected the receiver functions with a clear P-phase and stacked them according to their differences in slowness. Finally, we chose three stacked receiver functions to carry out the inversion.

\subsection{Joint inversion of receiver functions and surface waves}

The surface wave phase and group velocity dispersion curves are from Wang et al. (2014) and Fan et al. (2015). The origin of the surface wave dispersion technique is described in detail in their work. The dispersion curve is interpolated into each station. Generally, receiver function inversion has the advantage of obtaining the depth of seismic velocity

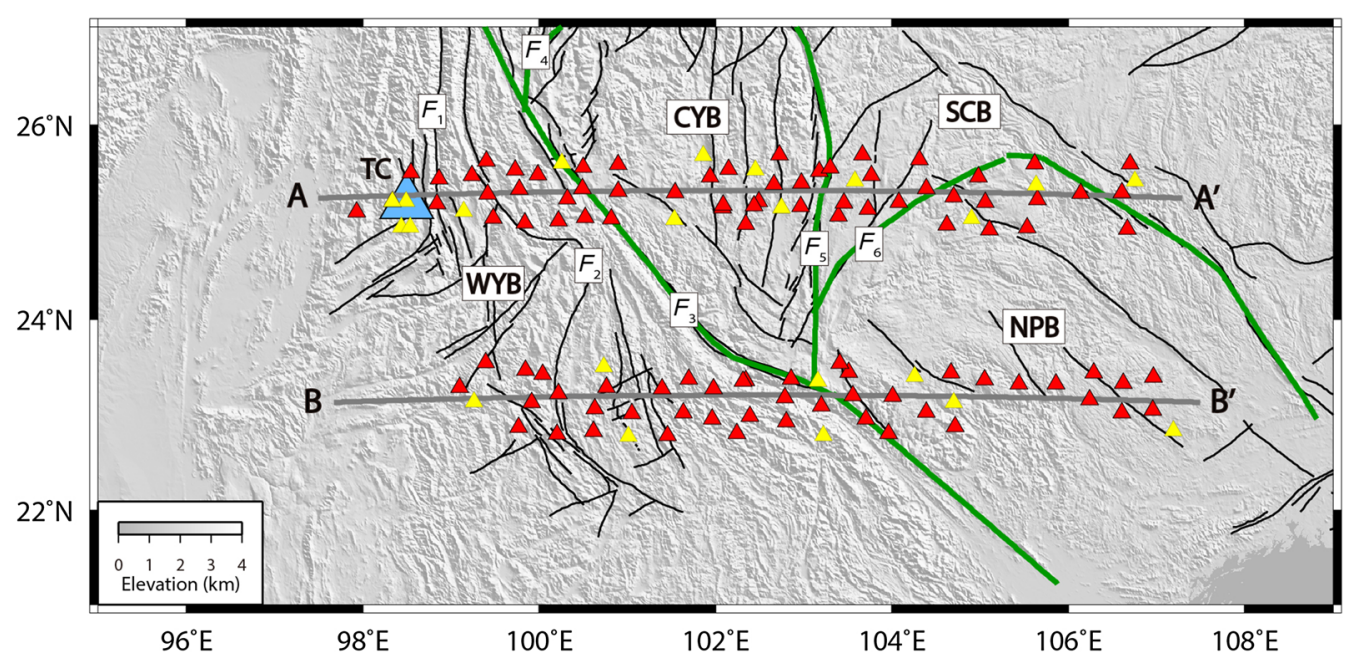

Fig. 2 Locations of the profiles and seismic stations. The red and yellow triangles represent the temporary and permanent stations, respectively. The blue triangle indicates the Tengchong volcanic area. Gray lines are the profiles $A A^{\prime}$ and $B B^{\prime}$ that were studied in this work. Black lines show the faults in the study area. $F_{1}$ Nujiang fault, $F_{2}$ Lancangjiang fault, $F_{3}$ Red River fault, $F_{4}$ Xiaojinhe fault, $F_{5}$ Xiaojiang fault, $F_{6}$ Mile fault, $T C$ Tengchong volcano 


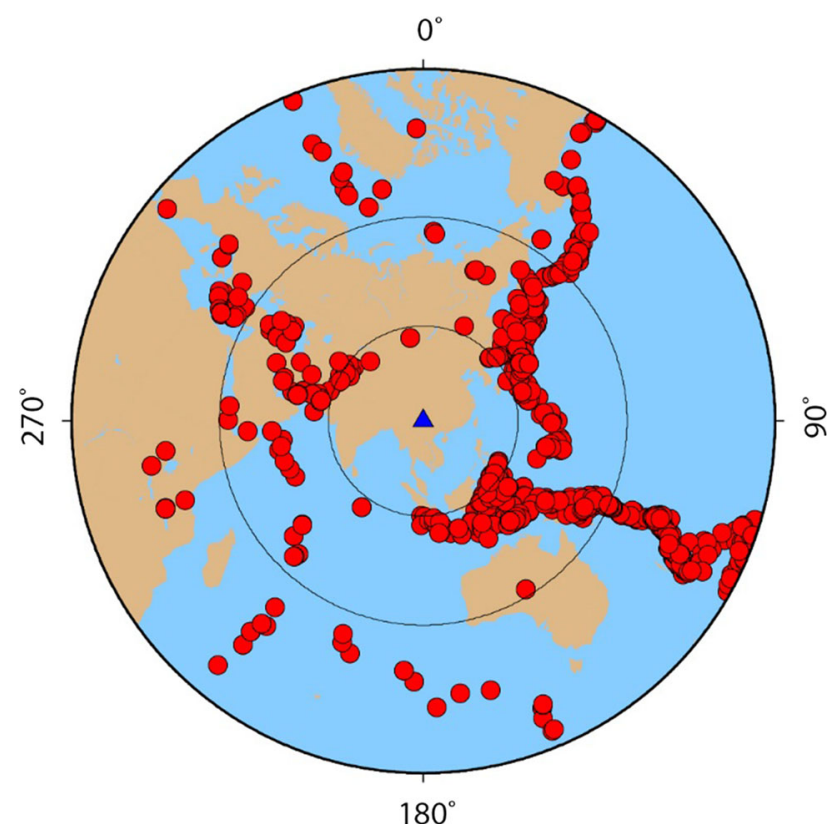

Fig. 3 Distribution of teleseismic events used for receiver functions. The red circles indicate teleseismic events. The blue triangle is the central point of the seismic stations used in this study

discontinuity. However, due to noise interference and multiple waves in the low-velocity layer near the surface, the calculated velocity structure is inaccurate. To solve this problem, we applied the surface wave dispersion curves to constrain the receiver function inversion. Surface wave dispersion curves should effectively reveal variation in $\mathrm{S}$-wave velocity, but it is difficult to determine the exact distribution of velocity discontinuity. Joint inversion of receiver functions and surface wave dispersion curves combines the advantages of the two methods and could allow us to obtain a reliable $\mathrm{S}$-wave velocity structure.

During joint inversion, the weight values of the fitting error for the receiver functions and the surface wave were 0.2 and 0.8 , respectively. The average $v_{\mathrm{P}} / v_{\mathrm{S}}$ ratio was also inverted in the inversion procedure. We used the same initial velocity model because the inversion results were not very sensitive to the initial model. With different initial models, the inversion results were similar. The initial $v_{\mathrm{S}}$ was set to $3.0 \mathrm{~km} / \mathrm{s}$ at $0-10 \mathrm{~km}, 3.3 \mathrm{~km} / \mathrm{s}$ at $10-26 \mathrm{~km}$, $3.5 \mathrm{~km} / \mathrm{s}$ at $26-34 \mathrm{~km}, 4.1 \mathrm{~km} / \mathrm{s}$ at $34-46 \mathrm{~km}$, and $4.5 \mathrm{~km} / \mathrm{s}$ at $46-200 \mathrm{~km}$. There were ten iterations for each station. From Fig. 4, it can be seen that the calculated receiver functions and surface wave dispersion curves at station 53,220 fit well with the observed data.

\section{Results}

With the dense seismic array deployed in this area, we obtained the S-wave velocity structures of the two profiles to a depth of $100 \mathrm{~km}$ (Figs. 5, 6). From profile $A A^{\prime}$ (Fig. 5), we could see that the Moho interface at the middle of the profile is deeper than that at both ends. The Moho depth decreases from about $46 \mathrm{~km}$ in the Central Yunnan block (CYB) to $34 \mathrm{~km}$ in the Nanpanjiang basin (NPB) and to $38 \mathrm{~km}$ in the WYB; and the topography and Moho depth have clear and good correspondence. Beneath the Xiaojiang fault (XJF), there is a crustal low-velocity zone (LVZ) located at 25-38 km depth. The LVZ has a length of $300 \mathrm{~km}$, crosses the XJF zone, and expands eastward about $160 \mathrm{~km}$ into the south China block (SCB). To its east, the NPB is shown to be of relatively high velocity within the crust and upper mantle. The LVZ passes through the XJF zone and seems to be resisted by the NPB, which is of high velocity; this result differs little from previous understanding that the XJF is the boundary of the high-velocity eastern region and low-velocity western region. In the Tengchong volcanic area, the velocity variation in the crust is more complex than that of its surroundings. On the whole, the crust shows alternate thin high-velocity zones (HVZ) and LVZs, and the upper mantle velocity is low. Between the Tengchong volcanic area and the XJF, the crustal velocity is relatively high, and the HVZ crosses the Red River fault (RRF). Profile $B B^{\prime}$ (Fig. 5) shows a conspicuous variation in velocity within the WYB and the NPB: the WYB has a wide range of crustal LVZs but NPB is shown to be of relatively high velocity. Compared with the northern profile, the Moho depths at the eastern stable block and western active block have quite gradual variations.

\section{Discussion}

Near the middle branch of the XJF, there exists a LVZ in the middle and lower crust and upper mantle. The crustal LVZ is located not only in the XJF; but also crosses the $\mathrm{XJF}$ and expands eastward into the SCB, which shows that the XJF is not the boundary of the eastern HVZ and western LVZ. Receiver function studies found that Poisson's ratio is high around the XJF (Wang et al. 2014). The surface heat flow is about $70 \mathrm{~mW} / \mathrm{m}^{2}$ near the middle branch of the XJF and its eastern area (Xu et al. 1992). Combined with the low velocity in the upper mantle, this implies that the crustal LVZ may be related to the high temperature in the upper mantle. When the temperature rises, the strength of the crustal material weakens, and then the crust easily deforms. Thus, we could speculate that with the high temperature near the XJF and its eastern area, the eastward extrusion of the Tibetan plateau may have passed through the XJF and affected its eastern region. The NPB is of relatively high velocity and has a low temperature (Xu et al. 1992) and low Poisson's ratio (Wang et al. 2014). We 

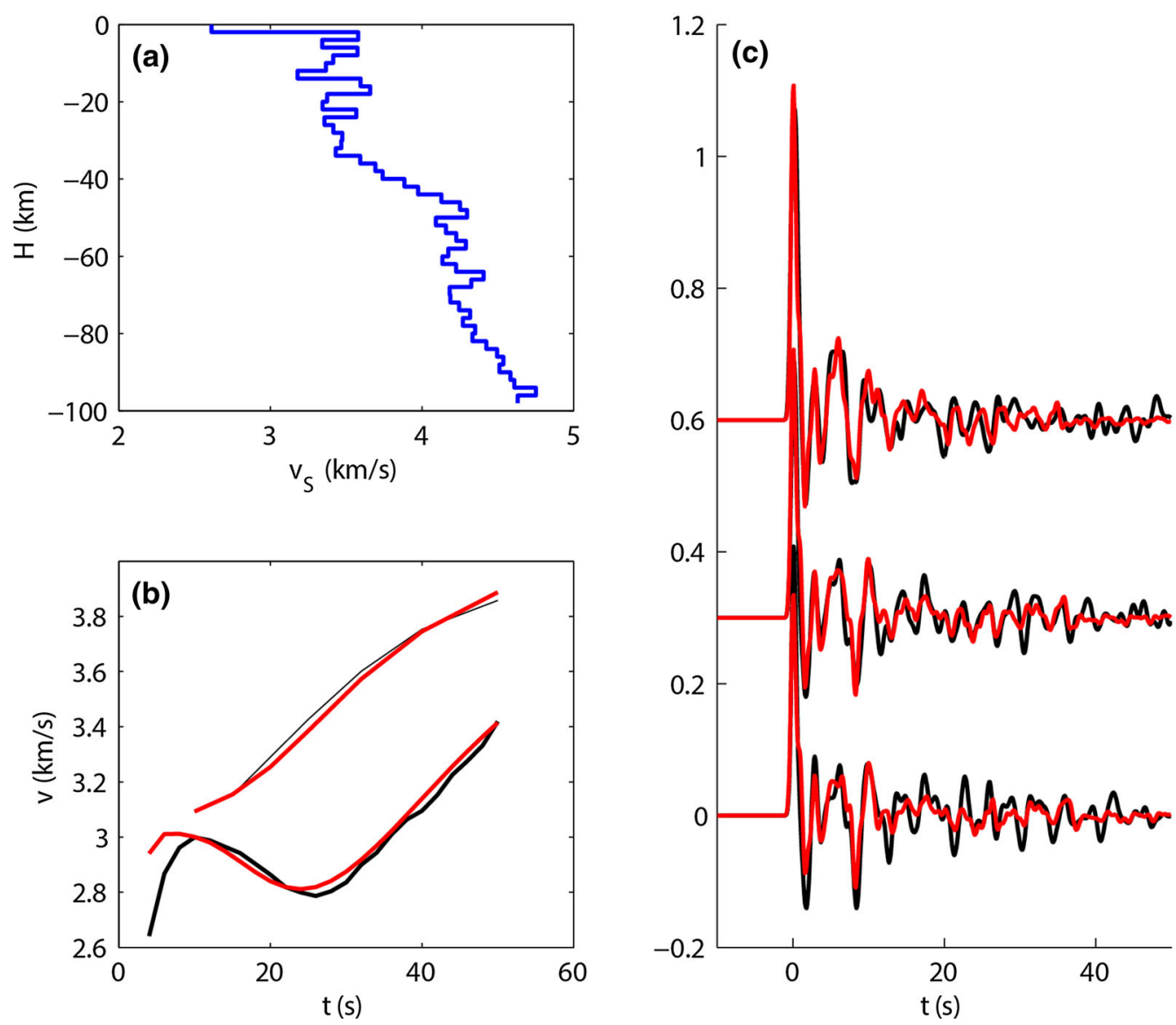

Fig. 4 The joint inversion results at station 53,220. a The S-wave velocity from joint inversion at station 53,220. b The surface wave dispersion curve (black lines) and their fit curves (red lines). c The original receiver functions (black lines) and their fit curves (red lines)

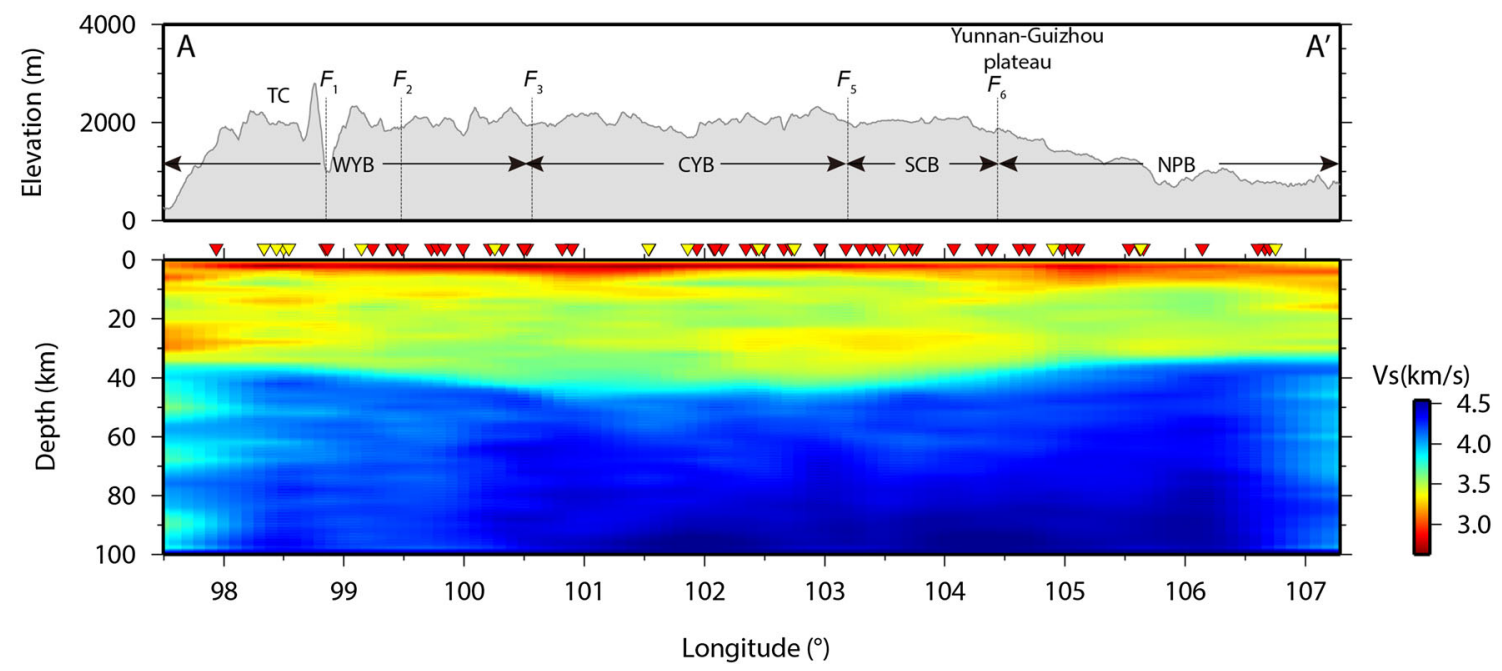

Fig. 5 The S-wave velocity structure beneath profile $A A^{\prime}$

consider that the rocks in the NPB have high strength, and so they block the eastward extrusion of the Tibetan plateau, causing topography uplift in the Yunnan-Guizhou plateau and crustal thickening. Wang et al. (2009) obtained the P wave velocity structure crossing XJF zone from the deep seismic sounding profile. The results implied that there 


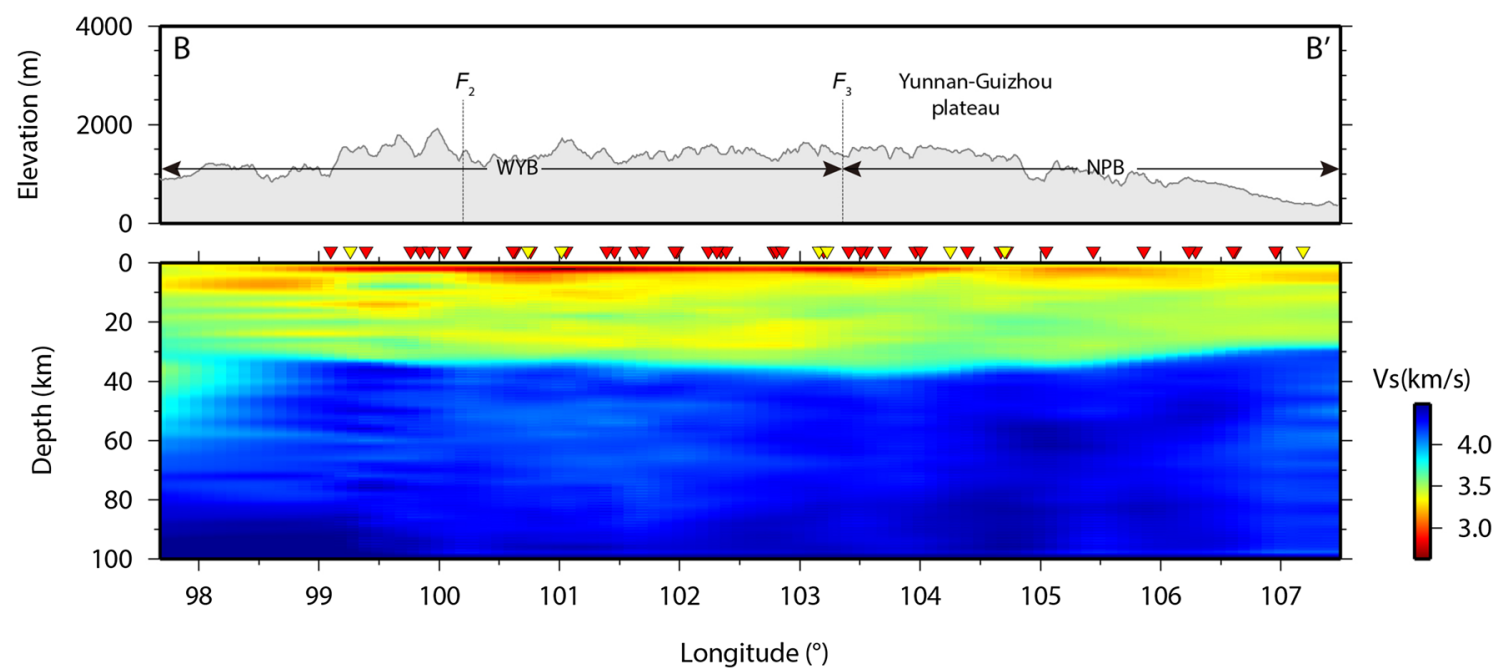

Fig. 6 The S-wave velocity structure beneath profile $B B^{\prime}$

exists LVZ in the lower crust beneath the east of XJF. Our results show that the crustal LVZ crosses XJF and presents in both sides of XJF zone, which is also identified from the P wave tomography (Wang et al. 2003; Wu et al. 2013).

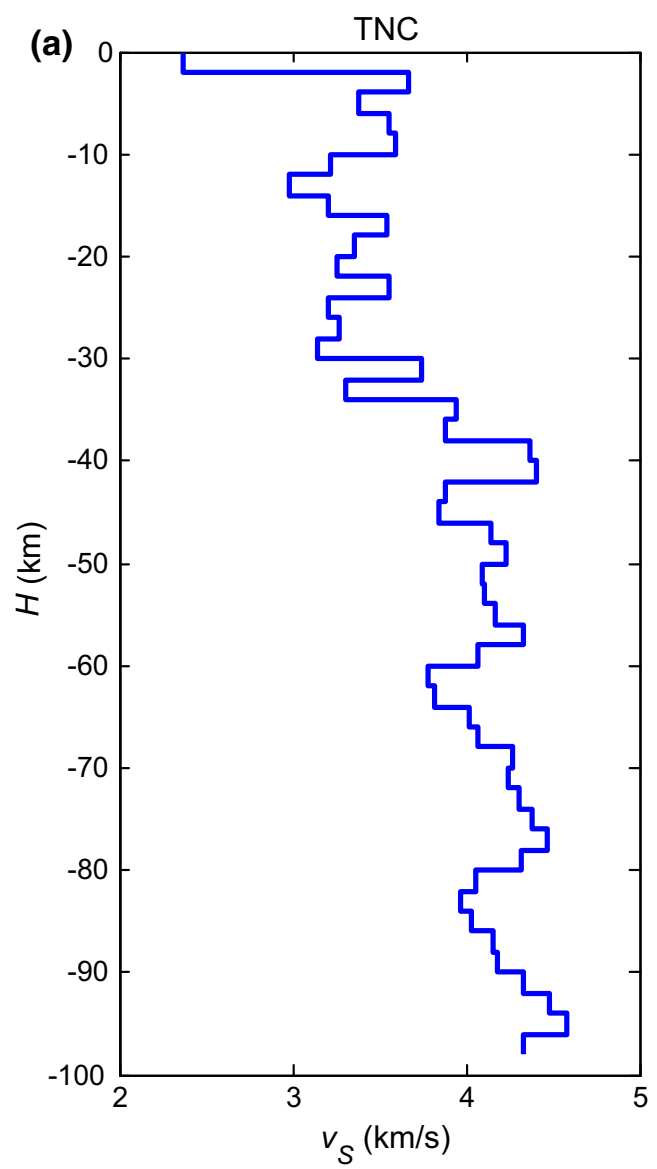

In the Tengchong volcanic area, the crustal velocity structure is shown to be more complex than that in other areas (Fig. 5). As shown in Fig. 7, the TNC and MIZ stations are both located in the Tengchong volcanic area. We

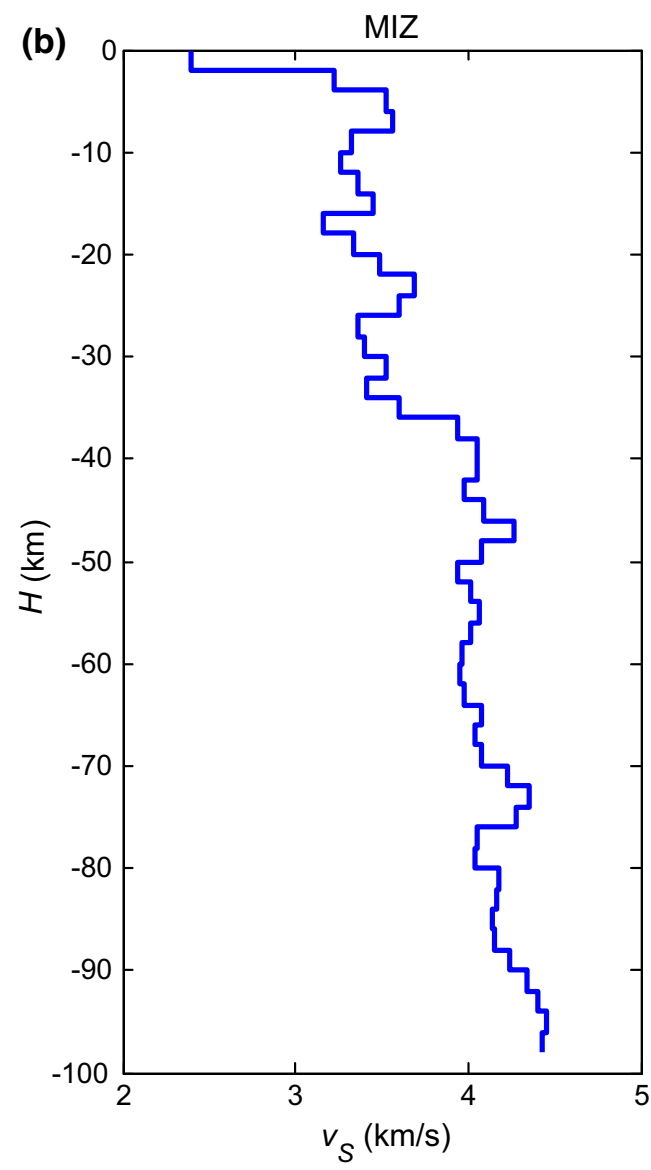

Fig. 7 The joint inversion results at TNC $\mathbf{a}$ and MIZ b stations 
can see that the shallow crust within $5-10 \mathrm{~km}$ is of high velocity, with $v_{\mathrm{P}}=3.6-3.7 \mathrm{~km} / \mathrm{s}$. Under the $\mathrm{HVZ}$, the velocity decreases rapidly and reaches to $3.0 \mathrm{~km} / \mathrm{s}$. From 16 to $23 \mathrm{~km}$, the crustal velocity rises again to about $3.6 \mathrm{~km} / \mathrm{s}$, and then the crust below $25 \mathrm{~km}$ is shown to have a relatively low velocity. Overall, the crustal velocity structure shows that HVZs alternate with LVZs, and the upper mantle has a low velocity. Moreover, the Tengchong volcanic area has a feature of high heat flow (Xu et al. 1992). Thus, it is speculated that the crustal LVZ is related to the high temperature and that the low-velocity hot material is mainly from the upper mantle. Several magma chambers may have developed in the crust after the intrusion of magma. When the magma cooled and solidified, the velocity of that rock became higher. We infer that the crustal high velocity anomaly is the main result of the intrusion of the basic or ultrabasic rocks from the deep lithosphere, and the alternation of HVZs and LVZs in the crust is the result of magmatic differentiation. Sun et al. (2014) obtained the S-wave velocity structure near our profile $A A^{\prime}$ with receiver functions and group velocity of Rayleigh wave. Both the results of our study and their work show that two crustal LVZs present beneath the Tengchong area and XJF zone. Sun et al. (2014) argued that the two LVZs are the channels of the crustal flow in the SE Tibetan plateau. In contrast to their results, our results show that there also exist HVZs clearly in the crust beneath Tengchong volcanic area. The results from deep seismic sounding profile and $\mathrm{P}$ wave tomography (Wang et al. 2002, 2003; Ma et al. 2008) also show the existence of both high velocity anomaly and low velocity anomaly in the crust beneath Tengchong volcanic area. Combining with the high temperature and low velocity within the upper mantle, we are inclined to conclude that the crustal lowvelocity material beneath Tengchong volcanic area is mainly from the deep lithosphere.

As shown in Fig. 5, between the Tengchong volcanic area and the XJF zone, the crustal velocity is shown to be relatively high. The level of seismicity in this area is weak (Xu et al. 2005). The heat flow (Xu et al. 1992), Poisson's ratio (Wang et al. 2014), and electrical conductivity (Bai et al. 2010) are lower than those in the surrounding areas. This implies that the rocks in this area have high strength and weak deformation. However, it is difficult to predict whether strong earthquakes could occur in such an area in the future. From Fig. 6, we could see that the average crustal velocity in the WYB is lower than that in the NPB, and a wide range of LVZs are distributed in the WYB, which is quite different from the situation in the NPB. The Moho depth varies more gradually than that in profile $A A^{\prime}$ (Fig. 5). Similar crustal thickness in the eastern stable block and western active block indicates that the deformation in the south of the study region is relatively weak.

\section{Conclusions}

We investigated the S-wave velocity structure beneath the SE Tibetan plateau by applying joint inversion of receiver functions and surface wave phase velocity and group velocity dispersion curves. The observation data are recorded at most of the permanent stations and from a dense seismic array. Combining our results with previous studies, we have shown some detailed and novel velocity anomalies. The major conclusions are as follows:

Beneath the XJF, there exists a crustal LVZ, which crosses the XJF and expands eastward into the SCB. The $\mathrm{LVZ}$ is related to hot material in the upper mantle. The high temperature has weakened the strength of the crust, contributing to eastward extrusion of the Tibetan plateau to passing through the XJF and affecting its eastern region. The rigid high-velocity NPB has resisted the eastward extrusion of the Tibetan plateau, causing crustal thickening and topography uplift in the Yunnan-Guizhou plateau.

In the Tengchong volcanic area, the crustal velocity structure is more complex than that of other regions. Crustal velocity is shown to be high at depths of 5-10 and $18-22 \mathrm{~km}$, and low at $10-18$ and $22-38 \mathrm{~km}$, and velocity is low in the upper mantle. We speculate that the crustal LVZ is related to the magma chambers in the crust. When the magma cooled and solidified, the velocity of the rocks became higher.

Between the Tengchong volcanic area and the XJF, the crustal velocity is relatively high. The seismicity level is clearly low compared with other regions. We consider that the strength of the rocks in this area is high and the deformation is weak. However, due to the complex tectonic activity in the SE Tibetan plateau, it is difficult to predict whether strong earthquakes will occur in this region in the future.

Acknowledgments The waveform data were provided by Data Management Center of China National Seismic Networks and China Seismic Array Data Management Center at the Institute of Geophysics, China Earthquake Administration. This work was supported by a National Natural Science Foundation of China (Grant No. 41374097) and China National Special Fund for Earthquake Scientific Research in Public Interest (Grant No. 201008001).

Open Access This article is distributed under the terms of the Creative Commons Attribution 4.0 International License (http://creative commons.org/licenses/by/4.0/), which permits unrestricted use, distribution, and reproduction in any medium, provided you give appropriate credit to the original author(s) and the source, provide a link to the Creative Commons license, and indicate if changes were made. 


\section{References}

Allegre CJ, Courtill V, Tapponnier P, Hirn A, Mattauer M, Coulon C, Jaeger JJ, Achache J, Scharer U, Marcoux J (1984) Structure and evolution of the Himalaya-Tibet orogenic belt. Nature 307(5946):17-22

Bai ZM, Wang CY (2004) Tomography research of the ZhefangBingchuan and Menglian-Malong wide-angle seismic profile in Yunnan province. Chin J Geophys 47(2):257-267 (in Chinese with English abstract)

Bai DH, Unsworth MJ, Meju MA, Ma XB, Teng JW, Kong XR, Sun Y, Sun J, Wang LF, Jiang CS (2010) Crustal deformation of the eastern Tibetan Plateau revealed by magnetotelluric imaging. Nat Geosci 3(5):358-362

Burg JP (1972) The relationship between maximum entropy spectra and maximum likelihood. Spectra Geophys 37(2):375-376

Cheng J, Xu XW, Gan WJ, Ma WT, Chen WT, Zhang Y (2012) Block model and dynamic implication from the earthquake activities and crustal motion in the southeastern margin of Tibetan Plateau. Chin J Geophys 55(4):1198-1212 (in Chinese with English abstract)

ChinArray (2006) China seismic array waveform data. China Earthq Adm. doi:10.12001/ChinArray.Data

ChinArray-Himalaya (2011) China seismic array waveform data of Himalaya project. Inst Geophys China Earthq Adm. doi:10. 12001/ChinArray.Data.Himalaya

Claerbout JF (1976) Fundamentals of geophysical data processing. McGraw-Hill, New York, pp 1-357

Fan LP, Wu JP, Fang LH (2015) The characteristic of Rayleigh wave group velocities in the southeastern margin of the Tibetan Plateau and its tectonic implications. Chin J Geophys 58:1555-1567 (in Chinese with English abstract)

Hu JF, Yang HY, Zhao H (2008) Structure and significance of S-wave velocity and Poisson's Ratio in the crust beneath the eastern side of the Qinghai-Tibet Plateau. Pure appl Geophys 165(5):829-845

Li YH, Wu QJ, Tian XB, Zhang RQ, Pan JT (2009) Crustal structure in the Yunnan region determined by modeling receiver functions. Chin J Geophys 52(1):67-80 (in Chinese with English abstract)

Liang S, Gan W, Shen C, Xiao G, Liu J, Chen W, Xiao D, Zhou D (2013) 3D velocity field of present-day crustal motion of the Tibetan Plateau derived from GPS measurements. J Geophys Res 118(10):5722-5732

Ma HS, Zhang GM, Wen XZ, Zhou LQ, Shao ZG (2008) 3-D $P$ wave velocity structure tomographic inversion and its tectonic interpretation in southwest China. Earth Sci 33(5):591-602 (in Chinese with English abstract)

Molnar P, Tapponnier P (1975) Cenozoic tectonics of Asia: effects of a continental collision. Science 189(4201):419-426

Qin JZ, Huang PG, Zhang JW (1998) Characteristics of $Q$ values around Tengchong volcano and adjacent areas. J Seismol Res 21:358-361 (in Chinese with English abstract)

Replumaz A, Tapponnier P (2003) Reconstruction of the deformed collision zone between India and Asia by backward motion of lithospheric blocks. J Geophys Res 108(B6):2285. doi:10.1029/ 2001JB000661

Rowley DB (1996) Age of initiation of collision between India and Asia: a review of stratigraphic data. Earth Planet Sci Lett 145(1-4):1-13
Royden LH, Burchfiel BC, King RW, Wang E, Chen Z, Shen F, Liu Y (1997) Surface deformation and lower crustal flow in Eastern Tibet. Science 276(5313):788-790

Shen F, Royden LH, Burchfiel BC (2001) Large-scale crustal deformation of the Tibetan Plateau. J Geophys Res 106(B4):6793-6816

Sun XX, Bao XW, Xu MJ, Eaton DW, Song XD, Wang LS, Ding ZF, Ning M, Yu DY, Hua L (2014) Crustal structure beneath SE Tibet from joint analysis of receiver functions and Rayleigh wave dispersion. Geophys Res Lett 41(5):1479-1484

Tapponnier P, Peltzer G, Dain AYL, Armijo R, Cobbold P (1982) Propagating extrusion tectonics in Asia: new insights from simple experiments with plasticine. Geology 10(12):611

Wang CY, Gang HF (2004) Crustal structure in Tengchong volcanogeothermal area, western Yunnan, China. Tectonophysics 380(1):69-87

Wang CY, Chan WW, Mooney WD (2003) Three-dimensional velocity structure of crust and upper mantle in southwestern China and its tectonic implications. J Geophys Res Solid Earth 108(B9):ESE 13-ESE 11

Wang CY, Han WB, Wu JP, Lou H, Chan WW (2007) Crustal structure beneath the eastern margin of the Tibetan Plateau and its tectonic implications. J Geophys Res Solid Earth 112(B7):3672

Wang CY, Lou H, Wang XL, Qin JZ, Yang RH, Zhao JM (2009) Crustal structure in Xiaojiang fault zone and its vicinity. Earthq Sci 22(4):347-356

Wang CY, Lou H, Wu JP, Bai ZM, Gang HF, Zheng QJ (2002) Seimological study on the crustal structure of Tengchong volcano-geothermal area. Acta Seismol Sin 24(3):231-242

Wang WL, Wu JP, Fang LH, Lai GJ, Yang T, Cai Y (2014) S wave velocity structure in southwest China from surface wave tomography and receiver functions. J Geophys Res Solid Earth 119(2):1061-1078. doi:10.1002/2013jb010317

Wu JP, Ming YH, Wang CY (2001) The S wave velocity structure beneath digital seismic stations of Yunnan province inferred from teleseismic receiver function modelling. Chin J Geophys 44(2):228-237 (in Chinese with English abstract)

Wu QJ, Tian XB, Zhang NL, Li WP, Zeng RS (2003) Receiver function estimated by maximum entropy deconvolution. Acta Seismol Sin 16(4):404-412 (in Chinese)

Wu JP, Yang T, Wang WL, Ming YH (2013) Three dimensional P-wave velocity structure around Xiaojiang fault system and its tectonic implications. Chin J Geophys 56(7):2257-2267 (in Chinese with English abstract)

Xu Q, Wang JA, Wang JC, Zhang WR (1992) Terrestrial heat flow and its tectonic significance in Yunnan, China. Geotectonica Et Metallogenia 16(3):285-299 (in Chinese with English abstract)

Xu Y, Yang JQ, Su YJ, Liu J (2005) Analysis on accurate location of earthquakes in Yunnan area and its tectonic meaning. J Seismol Res 28(4):340-344 (in Chinese with English abstract)

Zheng XF, Yao ZX, Liang JH, Zheng J (2010) The role played and opportunities provided by IGP DMC of China national seismic network in Wenchuan earthquake disaster relief and researches. Bull Seismol Soc Am 100(5):2866-2872 